\title{
INVESTIGATING THE ROLE OF ORGANIZATIONAL STRUCTURE COMPONENTS AND ITS IMPACT ON LOGISTICS SERVICE INNOVATION (CASE STUDY: CONSTRUCTION COMPANIES)
}

\author{
Mohammad Sadegh Hematyar Tabatabaie \\ Master Of Science Student, Department Of Management, Faculty Of Humanities, Kish Branch, Islamic \\ Azad University, Tehran, Iran \\ Azam Rahimi Nik \\ Assistant Professor, Department Of Management, Faculty Of Humanities, Tehran Markaz Branch, \\ Islamic Azad University, Tehran, Iran
}

\begin{abstract}
Innovation is one of the components that enable the organization to gain the competitive advantage. Innovation in the field of logistics has considerable advantages for the companies. Advantages such as accelerating the process of procurement, reducing the cost of warehousing or transportation, on time procurement of goods or materials, requiring less manpower, increasing the safety and accuracy and so on that all have been achieved through continuous improvement of processes and logistics functions. The aim of this study was to investigate the factors influencing the improvement of logistics innovation in terms of organizational structure. In terms of purpose, this study is an applied one, where the descriptive-survey method with the type of correlation was used to collect the data. The most important data collection tool was a questionnaire that was codified based on the Likert spectrum. Research community included all experts and authorities related to logistics, warehousing and procurement in active construction companies in Tehran that among them, 197 people were randomly selected. The collected information was analyzed by regression method and path analysis. This study has been consisted of four hypotheses that these hypotheses explain the relationship among the various components of the organizational structure and logistics innovation. The results indicated that the third hypothesis is confirmed. Thus, the organizational structure, especially the lack of focus and specialization on effective logistics innovation were reported and only recognition had no significant effect on logistics innovation. Also Logistics innovation was recognized as one of the factors affecting market performance.
\end{abstract}

Keywords: Logistics Innovation, Organizational Structure, Market performance, Construction companies

\section{INTRODUCTION}

Innovation, one of the most valuable assets of the organization, is a factor that enables organization by riding on the waves of change to surpass from its competitors. Kanter(1995) in his definition of innovation, has emphasized to the process of it and claims that innovation means process of gathering any new and useful ideas to resolve an issue and he believes that innovation, includes the formation of ideas, and is adoption and implementation of new ideas in processes, products and services. Williams (2001) argues that innovation is a factor that creates opportunities by individuals for themselves or for an organization where they work, regardless to the resources that are in their control. Innovation in organizations has various forms that generally are raised in the form of product innovation, service innovation, process innovation and market innovation. One of the innovations in the organizations that has recently taken in to consideration is innovation of logistics services. Logistics service innovation 
refers to the use of any idea, procedure, process or function in logistical operations of an organization. (Grawe and et al, 2009).Logistics means the management of the flow of goods or any other sources from the point of production or inventory location to the point of consumption. Logistics is commonly includes activities such as inventory management, transportation, warehousing, distribution of materials and products, displacement and maintaining the security of raw materials and prefabricated goods (Daugherty and et al, 2011). Intensity and competitive pressure which today is enter to the most of the industries, has caused companies to look for new ways to improve their logistics functions. Innovation in the field of logistics has had considerable advantages for the companies. Advantages such as accelerating the process of procurement, reducing the cost of warehousing or transportation, on time procurement of goods or materials, requiring less manpower, increasing security and accuracy, etc., which are all achieved by the continuous improvement of processes and logistics functions. These measures have been directly effective in improvement of profitability, reduction of production costs and improvement of the quality of the final product (Olson and et al 2005, Wagenr 2008, Daugherty and et al 2011). Although there is general agreement on the benefits of innovation development in all organizational areas, but the question that arises is that how innovation can be improved, particularly in the field of logistics services?

Numerous studies have been carried out about effective factors on innovation. In most of these studies, product innovation or process innovation is considered and logistics service innovation has been less investigated. However one of the main variables that from the perspective of some researchers (Daugherty et al., 2011; Bergfors and Larsson, 2009), has a positive impact on the improvement of logistics innovation is organizational structure, because the logistics operation, improves through higher flexibility and flexibility is greatly influenced by the organizational structure. From the perspective of these researchers, the organizational structure is effective on arrangement, work processes and usage of resources, so through this, it increases the capabilities of logistics service innovation. Also the organizational structure has influence on the discretion and the ability of individuals for making decisions and collaborating with each other, and through this, can be effective on the improvement of flexibility and individual competencies in the area of innovation (Daugherty et al., 2011). However, it still has not been raised a comprehensive approach in this regard, especially in the country that the subject of innovation has not been completely addressed, and we have seen inadequate attention to issues of logistics and innovation, whether by companies or by researchers and experts. In this study, it will be discussed that "whether the components of the organizational structure can be effective in improving the logistics service innovation?"

\section{LOGISTICS SERVICE INNOVATION}

Researchers define the organizational innovation as a revolutionary and evolutionary process that leads to a change in the organization. This change can occur in any of different components, including: policies, services, processes, systems, tools and products. The Researchers, know the logistics innovation as a process that through this, firms start to evaluate that what is valuable for customers, and then try to commit for learning these items (Flint and et al 2008). In other words, logistics innovation, is efforts of logistics-related units in line with the improvement of the components which are valuable for customers. The most important components of the logistics innovation in this definition are:

$\checkmark \quad$ The management of Learning in the field of supply chain

$\checkmark \quad$ Identifying that what is valuable for the customer

$\checkmark \quad$ Encouraging employees toward improvement of valuable components from the customer's perspective

Also it has been acknowledged that customers in this definition may be the other organizational units, for example, production unit, can be considered as customer of logistics unit. Researchers state that the innovation of logistics is the combination of different sources in the supply chain that will lead to higher levels of performance. The combination of sources includes primary sources, suppliers, purchased 
materials, arrangement and storage of cargo in the warehouses etc. In this study, Daugherty and et al model (2011) has been used to evaluate logistics service innovation that its components were:

$\checkmark \quad$ acceptance of innovation: Accepting innovation by managers and employees as a value and promoting it

$\checkmark \quad$ Senior management attention: Financial support and rewards and attention of management to the development of innovation

$\checkmark \quad$ Continuous improvement: Implementing mechanisms in order to improve processes and logistics procedures

$\checkmark \quad$ Variation and development of processes: Get ideas and creativities and convert them to new procedures and the development of logistics processes

\section{ORGANIZATIONAL STRUCTURE}

The organizational structure is called to the framework of relations that governs systems and organizational processes in a way that reflects the makeup of the components of an organization and determines the communication channels between the organizational components. By organizational structure, activities and organizational procedures will be organize and information flows will be regulate and it will be clear that Who is accountable to whom and who is responsible for special tasks(Hunter 2002). The organizational structure also represents the formal mechanisms of coordination and introduces organizational interaction patterns (Chatzaglu and et al 2011). In general, the organizational structure plays three basic functions in organizations that are: (De Marco and et al 2014)

$\checkmark \quad$ Separation of departments and units of the organization

$\checkmark \quad$ Distribution of functions among people

Coordination between organizational units

Daft (1379) believes that the dimensions of the organization are classified into two parts: structural and content. Structural dimensions express the internal features of an organization. They give basis that can measure and compare the organizations with each other. The content dimensions introduce the position of the organization and affect the structural dimensions. The dimensions of the organization have bilateral relationship with each other, and to reach the goals, adapt themselves to others. Generally the most important components of the structure are as follows:

- Official: It refers to the documentation that exists in the organization. In these documents, procedures, job descriptions, regulations, and policies that organizations must abide by and implement have written.

- Specialty: That is, to what extent or to what degree the works of the organization and its activities are divided into separate tasks.

- Having standard: The case that refers to the many of the same tasks that are done in a unified way.

- Hierarchy of authority: It means specifying the subject that each of the individuals to whom should give their work report. It also specifies the scope of control of any of the managers.

- Complexity: It means the number of the works or the sub-systems that are done within an organization.

- Being concentrated: In the hierarchy of authority, being concentrated is called on the level of authority that has decision-making power. When decisions are delegated to lower levels of the organization, it means that the organization is decentralized. 
- Personnel ratios: This ratio represents the application of people that for different tasks and various departments are hired in the organization. To calculate this ratio the number of employees or the number of groups of employees or the number of classes of employees are divided by the total number.

- being professional: Refers to the level of formal education and training of the employees. If employees in an organization need training to get a job in the long term, they say, that it is a highly professional organization (Kasraie and Alirahimie 1388).

One of the most common classifications of the components of the organizational structure is the classification of the Daugherty and et al (2011) that explains the components of the organizational structure as follows and this classification is used in this research:

- Decentralization: Refers to making decisions and delegation of authority in a wide range of organization and managers of different departments so that most decisions are not taken at the top.

- Recognition: Means the adoption of the laws and documented procedures of the organization in carrying out the activities and organizational measures.

- Specialization: Means using elite forces and specialists and for different positions in the organization focus on the expertise and avoiding from biased and selectively criteria.

- Complexity: Means the number of levels, the hierarchy of the organization, the organizational departments and the separation of units.

\section{STRUCTURAL IMPACT ON INNOVATION}

All organizations need exquisite and fresh comments and new ideas to be survive. New thoughts and ideas, like a soul in the body get blown and save the organization from destruction and annihilation. In our time, for being survive and for progressing and even for maintaining the status quo, the flow of renovation and innovation should be continued in the organization, to prevent it from stagnation and destruction. To continue the life in the turbulent and variable world, we must turn in to the creativity and innovation and the time that we are recognizing the changes and developments of the environment, we must prepare new responses to deal with them and with the influence of these changes, affect them and give them the desired shape (Marahmatie 1392). To create and encourage creativity in organizations as well as helping to foster the creative abilities of individuals in organizations, structural, humanitarian and cultural variables are effective (Zaki 2001). In research carried out by the Birus and the Dilbeck (1997) demonstrated that the organizational structure impacts on the organizational innovation. They have stated that the flexible structure not only leads to the development in the use of new ideas but also the innovation of these structures is much more than the innovation of the inflexible and rigid structures. Diel (1986) believes that the creation of creative and innovative environment is perhaps the most important factor in ensuring the survival of the organization to provide new and untapped ideas (Robinson 2011). Hashyld (1980) in his study has cited six important features for creative organizations: Freedom in expressing new ideas, flat organizational structure, information management, being aware from the contradictions, the needs of recruitment, competency and responsibility. He believes that only organizations with the above properties will be able to optimize the creative process and, therefore, will be successful in that field and only these organizations have appropriate structure to ensure their quite comprehensive creativity process (Peter, 2004). In general, the organizational structure states as one of the basic variables that can affect the level of creativity and innovation. From another point of view, the organization which tries to become an innovative organization must bring the following components in itself and in the absence of any of the following components the organizational innovation process may disrupt or face with difficulties. These components are (Marahmatie, 1392):

- Common vision of management and employees toward innovation 
- Widespread communication

- Suitable structure and the proportion between the organic and the mechanical sections of the structure

- High participation in innovation

- The people who can facilitate the innovation

- External focus (paying attention to the customer)

- Effective teamwork

- Creative atmosphere

- Development and continuity of individual progress

- learned organization

Although the organizational structure has been introduced as one of the factors affecting innovation but in most studies, yet, it is not clear that what is the proper structure for innovation improvement. Particularly the effect of direct components of organizational structure is not taken in to consideration on the improvement or decline of innovation. Accordingly, the hypotheses of this research, in order to investigate the role of triple components of organizational structure on logistics innovation are raised:

- Decentralization is significantly effective on improving the logistics service innovation

- Recognition is significantly effective on improving the logistics service innovation

- Specialization is significantly effective on improving the logistics service innovation.

-Logistics services innovation is significantly effective on improving the market performance

\section{RESEARCH METHODOLOGY}

In terms of purpose, this study is an applied one because its results are used directly in construction companies. Also the descriptive-survey method was used for this research. The Method of data collection was practical and the library one. The library method is used to extract and collect the basic information especially in the codification of the questionnaire. After codifying the questionnaire, the second method was used for gathering the basic information. The statistical population was: Experts and officials of the sections that were related to the logistics, warehousing and procurement in active construction companies in Tehran, 200 people were randomly selected and the required data were collected through questionnaires. The questionnaire was consisted of seven points Likert-type to directly investigate the hypotheses. In the following table the resources and the components related to each variable and Cronbach's alpha is observed:

Table 1: Variables, components and resources used in developing the questionnaire

\begin{tabular}{|c|c|c|c}
\hline Resource & Cronbach's alpha & Component & Variable \\
\hline $\begin{array}{c}\text { Daugherty and et al } \\
(2011)\end{array}$ & 0.845 & Decentralization & Organizational \\
\cline { 2 - 3 } & 0.769 & Recognition & Structure \\
\cline { 2 - 3 } & 0.820 & Specialization & \\
\cline { 2 - 4 } & 0.798 & & $\begin{array}{c}\text { Logistics } \\
\text { Innovation }\end{array}$ \\
\hline
\end{tabular}




\begin{tabular}{|l|l|l|l}
\hline & 0.864 & & $\begin{array}{c}\text { Market } \\
\text { performance }\end{array}$ \\
\hline
\end{tabular}

Cronbach's alpha coefficient values higher than 7/0 for all cases and this indicates the final approval of the evaluated items.

\section{DATA ANALYSIS}

First of all, to investigate the normality of distribution of data variables, Smirnov-Kolmogorov test was used. The purpose of it was to investigate the claim made regarding the normal distribution of data related to a quantitative variable that is one of the prerequisites of regression testing.

Table 2: Kolmogorov-Smirnov

\begin{tabular}{|c|c|c|c|c|c|}
\hline $\begin{array}{c}\text { Logistics } \\
\text { innovation }\end{array}$ & $\begin{array}{c}\text { Market } \\
\text { performance }\end{array}$ & Decentralization & Recognition & Specialization & \\
\hline 4.2177 & 4.1134 & 4.1104 & 4.2183 & 4.0629 & Average \\
.775 & 1.192 & 1.066 & 1.198 & 1.207 & KS statistics \\
.586 & .116 & .206 & .114 & .108 & sig \\
\hline
\end{tabular}

The results show that the data distribution is normal on all items, because according to the results, the significance level of Sig for all of the variables is more than the significance level of 0.05 . So with $95 \%$ confidence the $\mathrm{H} 0$ hypothesis is not rejected and the distribution of the data is normal. Also the statistic value of $Z$ is smaller than the values in the table so this emphasizes to the normality of the data. Normality of the data tells us that in order to assess hypotheses, parametric tests should be used. So in order to measure the correlation, Pearson correlation index is used.

Table 3: Investigating the correlation Test

\begin{tabular}{|c|c|c|c|c|c|c|c|}
\hline $\begin{array}{l}\text { Degrees } \\
\quad \text { of } \\
\text { freedom }\end{array}$ & $\begin{array}{l}\text { The } \\
\text { coefficient of } \\
\text { determination }\end{array}$ & sig & $\begin{array}{r}\text { Pearson } \\
\text { coefficient }\end{array}$ & Number & $\begin{array}{r}\text { The } \\
\text { dependent } \\
\text { variable }\end{array}$ & $\begin{array}{r}\text { The } \\
\text { independent } \\
\text { variable }\end{array}$ & Hypothesis \\
\hline 196 & $0 / 25$ & .000 & $508^{* *}$ & 197 & $\begin{array}{r}\text { Logistics } \\
\text { service } \\
\text { innovation }\end{array}$ & Decentralization & 1 \\
\hline 196 & & 0324 & 071 & 197 & $\begin{array}{r}\text { Logistics } \\
\text { service } \\
\text { innovation }\end{array}$ & Recognition & 2 \\
\hline 196 & $\mathbf{0} / \mathbf{1 1}$ & .000 & $337^{* *}$ & 197 & $\begin{array}{r}\text { Logistics } \\
\text { service } \\
\text { innovation }\end{array}$ & Specialization & 3 \\
\hline 196 & 0/07 & .000 & $.282^{* *}$ & 197 & $\begin{array}{r}\text { Market } \\
\text { performance }\end{array}$ & $\begin{array}{r}\text { Logistics } \\
\text { service } \\
\text { innovation }\end{array}$ & 4 \\
\hline
\end{tabular}


The results show that there is a significant and positive relationship between "decentralization" and "logistics innovation". Pearson correlation coefficient is equal to 508/0 that indicates the strong relationship which at level of 99 percent is significant because the level of sig is reported less than 05/0. So the first correlational relationship of the research is approved. In the following, the result of the first hypothesis by the use of regression test will be discussed. In the second equation, the results show that there is no significant relationship between "Recognition" and "logistics innovation". Pearson correlation coefficient is equal to $071 / 0$, which indicates that the type of relationship is very weak, which in level of 95 percent, is not significant because the level of sig is reported more than $05 / 0$. So the first correlational relationship of the research is not approved and certainly can be said that the second hypothesis is rejected. About the third hypothesis, the results show that there is a significant and positive relationship among "specialization" and "logistics innovation". The same thing is true about the fourth equation and the correlational relationship is accepted. In the next step it becomes clear that which of these relationships are approved.

\section{REGRESSION TEST AND DETERMINING THE NON-LINEAR EQUATION FOR THE FIRST HYPOTHESIS}

In order to find the regression equation, first you have to recognize which state of non-linear equation or linear equation is the most appropriate one to determine the equation. This is done with the help of ANOVA test.

Table 4: ANOVA test, the first hypothesis and calculation of the coefficients

\begin{tabular}{|c|c|c|c|c|c|c|c|c|c|}
\hline & & \multicolumn{4}{|c|}{ Summary of the model } & & \multicolumn{3}{|c|}{ Calculation of the coefficients } \\
\cline { 2 - 9 } Equation & R Square & $\mathrm{F}$ & $\mathrm{df1}$ & $\mathrm{df2}$ & Sig. & $\begin{array}{c}\text { Constant } \\
\text { coefficie } \\
\text { nt }\end{array}$ & b1 & b2 & B3 \\
\hline $\begin{array}{c}\text { Linear } \\
\text { equation }\end{array}$ & .258 & 67.560 & 1 & 194 & .000 & 2.679 & .374 & & \\
\hline $\begin{array}{c}\text { Logarithm } \\
\text { equation }\end{array}$ & .267 & 70.737 & 1 & 194 & .000 & 2.175 & 1.469 & & \\
\hline Reverse & .262 & 68.739 & 1 & 194 & .000 & 5.544 & -5.188 & & \\
\hline Quadratic & .268 & 35.397 & 2 & 193 & .000 & 1.681 & .884 & -.062 & \\
\hline The Grade 3 & .269 & 23.504 & 3 & 192 & .000 & 2.190 & .476 & .041 & -.008 \\
\hline Compound & .264 & 69.624 & 1 & 194 & .000 & 2.838 & 1.098 & & \\
\hline power & .277 & 74.348 & 1 & 194 & .000 & 2.494 & .369 & & \\
\hline S curve & .275 & 73.577 & 1 & 194 & .000 & 1.763 & -1.313 & & \\
\hline Growth & .264 & 69.624 & 1 & 194 & .000 & 1.043 & .093 & & \\
\hline Exponential & .264 & 69.624 & 1 & 194 & .000 & 2.838 & .093 & & \\
\hline logistic & .264 & 69.624 & 1 & 194 & .000 & .352 & .911 & & \\
\hline
\end{tabular}

F with the significant amount of $\mathrm{Sig}=.000$ is highly significant in all cases and the hypothesis of the equation is established. Then, quantities of $F$ for different equations are compared. As it can be seen, the amount of $\mathrm{F}$ for the equation of power is more than other cases. So in this case, the equation of power may be the best mode. According to the right half of the table, constant coefficient is equivalent to 494/2 and variable coefficient is equivalent to $369 / 0$, thus, the non-linear equation of power can be provided as follows: 


\section{$\operatorname{Ln} y=\operatorname{Ln} 2 / 494+0 / 369 \operatorname{Ln} x$}

Ln $\mathrm{x}$ is the natural logarithm of $\mathrm{X}$. According to the above non-linear equation we can say that the decentralization is effective on logistics innovation. Therefore the first research hypothesis is confirmed. In the following figure, the histogram on the relationship between these two variables is visible:

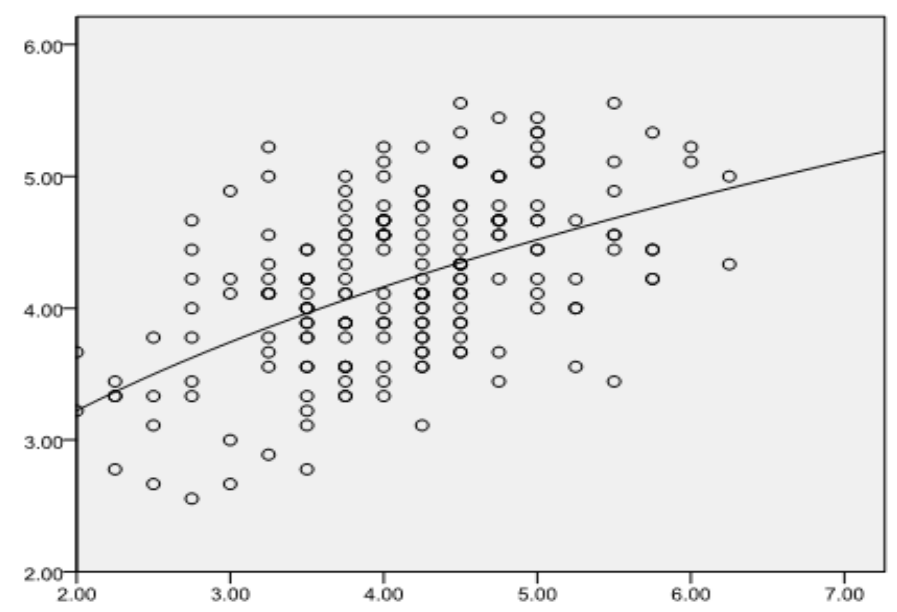

Figure 1: Power regression equations in the first hypothesis

This graph shows that when the centralization reduces, at the same time the innovation improves on a smaller scale.

\section{REGRESSION TEST AND DETERMINING THE NON-LINEAR EQUATION FOR THE THIRD HYPOTHESIS}

About the test of the third hypothesis, the amount of $\mathrm{F}$ with the high significant level Sig $=.000$ is highly significant in all cases and the hypothesis of the equation is established. Then, the quantities of $F$ for different equations are compared. As it can be seen, the amount of $\mathrm{F}$ for the equation of power is more than other cases. So in this case, the equation of power may be the best mode.

Table 5: ANOVA test, the third Hypothesis and calculation of the coefficients

\begin{tabular}{|c|c|c|c|c|c|c|c|c|}
\hline & \multicolumn{5}{|c|}{ Summary of the model } & \multicolumn{3}{|c|}{ Calculation of the coefficients } \\
\hline & & & & & & $\begin{array}{c}\text { Constant } \\
\text { coefficie } \\
\text { Et }\end{array}$ & b1 & b2 \\
\hline
\end{tabular}




\begin{tabular}{|c|c|c|c|c|c|c|c|c|c|}
\hline $\begin{array}{c}\text { Linear } \\
\text { equation }\end{array}$ & .113 & 24.809 & 1 & 194 & .000 & 3.072 & .282 & & \\
\hline $\begin{array}{c}\text { Logarithm } \\
\text { equation }\end{array}$ & .107 & 23.347 & 1 & 194 & .000 & 2.778 & 1.041 & & \\
\hline Reverse & .094 & 20.079 & 1 & 194 & .000 & 5.106 & -3.466 & & \\
\hline Quadratic & .113 & 12.342 & 2 & 193 & .000 & 3.109 & .263 & .002 & \\
\hline Grade 3 & .157 & 11.875 & 3 & 192 & .000 & 12.369 & -7.268 & 1.962 & -.164 \\
\hline Compound & .118 & 26.044 & 1 & 194 & .000 & 3.122 & 1.074 & & \\
\hline power & .113 & 28.598 & 1 & 194 & .000 & 2.897 & .263 & & \\
\hline S curve & .099 & 21.279 & 1 & 194 & .000 & 1.653 & -.879 & & \\
\hline Growth & .118 & 26.044 & 1 & 194 & .000 & 1.139 & .071 & & \\
\hline Exponential & .118 & 26.044 & 1 & 194 & .000 & 3.122 & .071 & & \\
\hline Logistics & .118 & 26.044 & 1 & 194 & .000 & .320 & .931 & & \\
\hline
\end{tabular}

According to the right half of the table, the constant coefficient is equivalent to $2 / 897$ and the variable coefficient is equivalent to $0 / 263$, thus, the non-linear equation of power can be provided as follows:

$$
\operatorname{Ln} y=\operatorname{Ln} 2 / 897+0 / 263 \operatorname{Ln} x
$$

Ln $\mathrm{x}$ is the natural logarithm of $\mathrm{X}$. According to the above non-linear equation we can say that the Specialization is effective on logistics innovation and the third research hypothesis is confirmed. In the following figure, the histogram on the relationship between these two variables is visible:

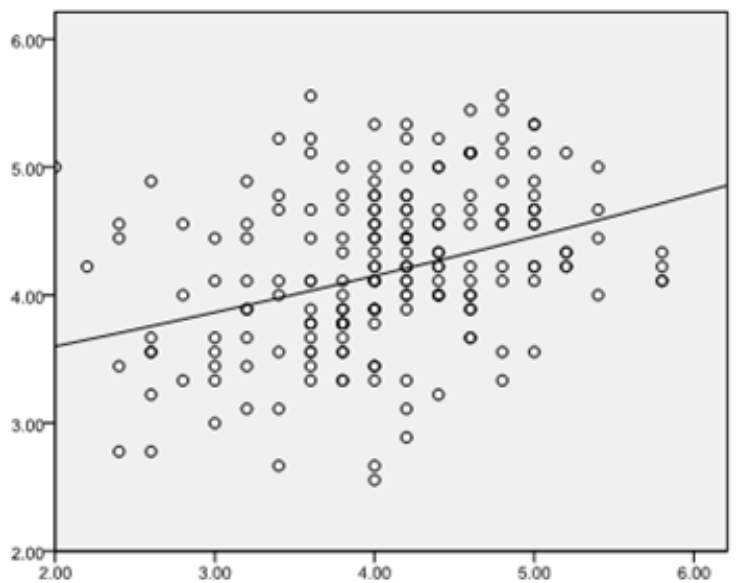

Figure 2: Power regression equations in the third hypothesis

\section{REGRESSION TEST AND DETERMINING THE NON-LINEAR EQUATION FOR THE FOURTH HYPOTHESIS}

About the test of the fourth hypothesis, the amount of $\mathrm{F}$ with the high significant level Sig $=.000$ is highly significant in all cases and the hypothesis of the equation is established. Then, the quantities of $\mathrm{F}$ for different equations are compared. As it can be seen, the amount of $\mathrm{F}$ for the logarithm equation is more than other cases. So in this case, the logarithm equation may be the best mode. 
Table 6: ANOVA analysis, the fourth Hypothesis and the calculation of the coefficients

\begin{tabular}{|c|c|c|c|c|c|c|c|c|c|}
\hline \multirow[t]{2}{*}{ Equation } & \multicolumn{5}{|c|}{ Summary of the model } & \multicolumn{4}{|c|}{ Calculation of the coefficients } \\
\hline & R Square & $\mathrm{F}$ & df1 & $\mathrm{df2}$ & Sig. & $\begin{array}{r}\text { Constant } \\
\text { coefficie } \\
n t\end{array}$ & b1 & b2 & B3 \\
\hline $\begin{array}{l}\text { Linear } \\
\text { equation }\end{array}$ & .080 & 16.787 & 1 & 194 & .000 & 2.761 & .323 & & \\
\hline $\begin{array}{l}\text { Logarithm } \\
\text { equation }\end{array}$ & .082 & 17.233 & 1 & 194 & .000 & 2.234 & 1.323 & & \\
\hline Reverse & .082 & 17.220 & 1 & 194 & .000 & 5.379 & -5.171 & & \\
\hline Quadratic & .082 & 8.625 & 2 & 193 & .000 & 1.579 & .905 & -.070 & \\
\hline Grade 3 & .082 & 8.625 & 2 & 193 & .000 & 1.579 & .905 & -.070 & .000 \\
\hline Compound & .072 & 15.059 & 1 & 194 & .000 & 2.894 & 1.083 & & \\
\hline power & .074 & 15.610 & 1 & 194 & .000 & 2.534 & .329 & & \\
\hline S curve & .075 & 15.757 & 1 & 194 & .000 & 1.714 & -1.293 & & \\
\hline Growth & .072 & 15.059 & 1 & 194 & .000 & 1.063 & .080 & & \\
\hline Exponential & .072 & 15.059 & 1 & 194 & .000 & 2.894 & .080 & & \\
\hline Logistics & .072 & 15.059 & 1 & 194 & .000 & .346 & .923 & & \\
\hline
\end{tabular}

According to the right half of the table, the constant coefficient is equivalent to $2 / 234$ and the variable coefficient is equivalent to $1 / 323$, thus, the non-linear logarithm equation can be provided as follows:

$$
y=2 / 234+1 / 323 \ln x
$$

Ln $\mathrm{x}$ is the natural logarithm of $\mathrm{X}$. According to the above non-linear equation we can say that the logistics innovation is effective on market performance and the fourth research hypothesis is confirmed. In the following figure, the histogram on the relationship between these two variables is visible: 


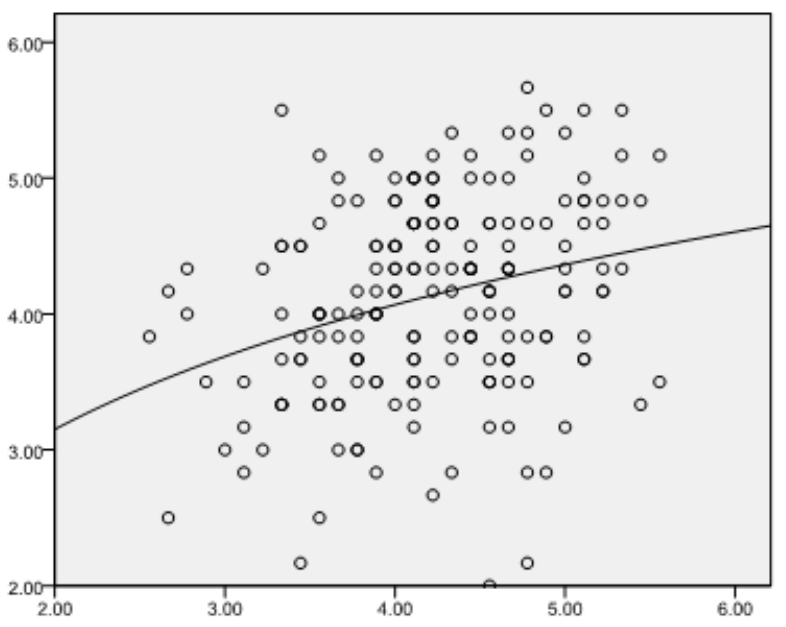

Figure 3: Power regression equations in the fourth hypothesis

This graph shows that the improvement of logistics innovation causes rapid improvement for market performance.

\section{RESULTS}

This study has been consisted of four hypotheses that these hypotheses explain the relationship between the components of the organizational structure with the logistics innovation and market performance. After gathering the information and checking the hypotheses, it was found that 3 hypotheses are confirmed and of course, one hypothesis rejects. The results show that the decentralization is strongly and in a meaningful form effective on the improvement of the logistics innovation. It seems that the delegation of authority to the employees and their involvement in making decisions can lead to the development of creativity and ideas. In general, the centralization refers to the levels of the organization and decision-making center. The Centralized organizations make most of their decisions through hierarchy of command and in decentralized organization the decisions are made with the participation of subordinates. The results showed that the situation of the logistics innovation is potentially better in decentralized organizations. In the case of reason it can be stated that the amount of communication, participation in job and satisfaction is higher in decentralized companies and these factors increase the level of creativity and efficiency. Also the results show that the recognition rate is not effective on the innovation of logistics. The relationship between these two variables is very weak and insignificant. Recognition is referred to the necessity and the use of regulations, procedures, instructions and duties that they specify the framework, duties and the responsibilities of the staff. There are two points of view regarding the recognition, at the first one, the recognition only contains the written official rules and regulations, and in the second view, the rules and customary principles are added in to the definition of recognition. Although most of the studies indicate that the recognition undermines the innovation and reduces the communication within the organization but in this study, recognition was known as a neutral and ineffective variable. In fact, it seems that in these organizations, the presence or absence of rules and procedures and their extension had not any role in the improvement or lack of improvement of the innovation. In addition, the results show that specialization is effective on the improvement of logistics innovation. Specialization Means using the professional and elite forces and the centrality of specialization for the appointments of positions and avoiding from the biased and selective criteria. It seems that when the specialized and experienced personnel are employed in positions related to logistics, the level of logistics innovation improves. In general, it is natural that innovation occurs more by professionals and skilled personnel. The reason for this is that these people have higher recognition from the job components and better know the dimensions of their work. Thus they can better improve these components. 
Based on the research findings, Logistics innovation is also effective on the improvement of the performance of the enterprise market. In fact, efforts to improve logistics innovation directly lead to improvement of the performance of organizations in the field of marketing. Innovation is very important in using the competitive benefits, especially in large organizations, because the organizations will be deleted from the competition arena without continuous innovation. Currently, more than half of the profits of non-governmental organizations, especially in the advanced technology industries and organizations, as the information and communication technology industry, are obtained from the products and services that are less than five years old. Furthermore, Innovation has increased in different sectors of trade and services and the companies are trying to maintain their competitive advantages in this environment. Therefore, innovation is very important for competitiveness in the fields of trade and services. From another perspective, coordination and adaption of organizations with the complex environment that has surrounded them is vital and inevitable. The essential condition of this important work is innovation and all organizations for survival, need innovative and new ideas. New ideas are blown like a spirit in the body of the organization and will save it from annihilation and destruction. Organizational innovation almost includes the critical aspects of the organization, mechanisms, processes, activities and micro and macro aspects of the organization. In a world that is rapidly changing, inertia and lack of innovation for organizations bring nothing except failure; therefore, organizations in this area should create the necessary conditions.

\section{SUGGESTIONS}

In order to improve logistics innovation, decentralization should be considered as the main solution. In fact, the most important component of the organizational structure that is effective on the improvement of innovation is decentralization. In this regard, it is suggested that:

$\checkmark \quad$ Employees must have greater freedom to carry out their activities and pursue their business processes.

$\checkmark \quad$ Working programs must be flexible and rotatable and changeable and providing the strict and inflexible working programs should be avoided.

$\checkmark \quad$ Empowering the employees and delegating more authority to them

Specialization also was discussed as one of the effective variables on the improvement of the logistics innovation. On this basis, it is suggested that:

$\checkmark \quad$ The logistics personnel must be selected from the experienced and graduated people of this field and the personnel of the other units should not be used in this field.

$\checkmark \quad$ Staff must continuously be encouraged for the improvement of their abilities and job-related skills.

$\checkmark \quad$ Staff must be employed only in their specialized fields

$\checkmark \quad$ Job skills must be considered as a determining factor in selecting people for positions related to the logistics.

The most important conclusion of the study is emphasizing the positive role of the logistics innovation on the improvement of the market performance. So it is necessary to provide recommendations for improving the logistics innovation:

$\checkmark$ Development programs related to the logistics innovation must be implemented in the organizations and the components of the logistics innovation must receive serious attention from the managers.

$\checkmark \quad$ Encouraging employees to provide and develop ways in order to provide new services in the field of the logistics especially the projects which lead to customer satisfaction. 
$\checkmark \quad$ Development of programs in order to improve the methods of providing raw materials for the new products.

$\checkmark \quad$ Development of methods and the warehouse processes related to the material supply.

$\checkmark \quad$ Encouraging the employees of the logistics unit to creativity and innovation.

$\checkmark \quad$ Annual development of the plans and new ideas in the field of storage and providing the raw materials. 